\title{
Factors affecting the development of recurrence in stage I low grade - endometrial stromal sarcoma; multicentre retrospective study
}

\section{Evre I düşük dereceli - endometrial stromal sarkomda nüks gelişimi üzerine etki eden faktörler; çok merkezli retrospektif çalışma}

\author{
Varol Gülseren, Mustafa Kocaer, Anıl Turhan Çakır, Müge Harma, Mehmet İbrahim Harma, İsa Aykut \\ Özdemir, Muzaffer Sanc1, Kemal Güngördük \\ ${ }^{1}$ Kaman Devlet Hastanesi, Kadın Hastalıkları ve Doğum Bölümü, Kırşehir, Türkiye. \\ ${ }^{2}$ Tepecik Eğitim ve Araştırma Hastanesi, Kadın Hastalıkları ve Doğum Bölümü, İzmir, Türkiye. \\ ${ }^{3}$ Bülent Ecevit Üniversitesi, Kadın Hastalıkları ve Doğum Bölümü, Zonguldak, Türkiye. \\ ${ }^{4}$ Bakırköy Sadi Konuk Eğitim ve Araştırma Hastanesi, Kadın Hastalıkları ve Doğum Bölümü, İstanbul, Türkiye. \\ ${ }^{5}$ Muğla Sttkı Koçman Üniversitesi, Kadın Hastalıkları ve Doğum Bölümü, Muğla, Türkiye.
}

\section{ÖZET}

GIRIŞ ve AMAÇ: Nadir görülen ve iyi prognoza sahip olan evre I düşük grade-endometrial stromal sarkom (LG-ESS) hastalarının incelenmesi ve nüks oluşumuna etki eden prognostik faktörlerin değerlendirilmesidir. YÖNTEM ve GEREÇLER: Tepecik eğitim ve araştırma hastanesi ve Zonguldak Bülent Ecevit üniversitesi tıp fakültesinde, evre I LG-ESS tanısı alan ve takiplere gelen 24 hasta retrospektif olarak incelendi. Çalışmaya 1998-2016 yılları arasında, ameliyat ve takiplerini bu iki merkezde olan hastalar dahil edildi. Çalışmaya alınmama kriterleri; endometrial stromal nodül veya farklılaşmamış stromal sarkom histolojik tipler, evre II,III ve IV ESS, eşlik eden başka malignitelerin olması ve takiplere gelmeyen hastalar.

BULGULAR: Yaş, adjuvan radyoterapi (RT), myometrial invazyon (MI), tümör boyutu ve mitoz sayısının lojistik regresyon analizine göre evre I LG-ESS hastalarında takipte nüks oluşma riski üzerine etkileri incelendi ve on büyük büyütme alanında $\geq 5$ mitoz olması nüks riskini saptamada anlamlı ilişkili olduğu görüldü. Prognostik faktörlerin Hastalıksız (DFS) ve toplam sağkalım (OS) sonuçları üzerine etkileri araştıııldı ancak istatistiksel olarak anlamlı etki eden faktör olmadığı saptandı. Evre I, LG-ESS hastalarının, 5 yıllık OS \%100, 10 y1llık OS \%86.2 ve 5 yıllık DFS \%91.7 ve 10 ylllı DFS \%85.1 olarak hesaplandi.

TARTIŞMA ve SONUÇ: LG-ESS hastaları mükemmel prognoza sahiptir ve adjuvan RT tedavisi prognoz üzerine etki etmemektedir. Sağkalım süreleri uzun olan bu hastalarda adjuvan RT işlemi nüks tedavisine saklanmalıdır.

Anahtar Kelimeler: Endometrial stromal sarkom, Ameliyat, Nadir tümör

\section{ABSTRACT}

INTRODUCTION: To investigate patients with stage I, low-grade endometrial stromal sarcoma (LG-ESS) which is rare and has good prognosis and to evaluate prognostic factors affecting recurrence. METHODS: Twenty-four patients with stage I LG-ESS diagnosis and followed-up in Tepecik Education and Research hospital and medical faculty of Zonguldak Bülent Ecevit University were investigated as retrospective. Patients who had undergone surgery and had follow-up at these two centers between 1998 and 2016 were included in the study. Exclusion criteria were endometrial stromal nodule or undifferentiated stromal sarcoma histologic types, stage II, III and IV ESS, accompanying malignancies and non-follow-up patients. RESULTS: The effects of age, adjuvant radiotherapy (RT), myometrial invasion (MI), tumor size and number of mitotic figures on the recurrence risk of patients with stage I LG-ESS in follow-up were analyzed according to logistic regression analysis and it was found that there was a significant correlation between the risk of recurrence and presence of $\geq 5$ mitosis in 10 microscopic high power fields. The effects of prognostic factors on disease free (DFS) and overall survival (OS) outcomes were investigated, but there was no statistically significant factor. 5-year OS and 10-year OS for Stage I, LG-ESS patients were calculated as $100 \%$ and $86.2 \%$, respectively; 5-year DFS and 10-year DFS for those patients were $91.7 \%$ and $85.1 \%$, respectively. 
DISCUSSION and CONCLUSION: LG-ESS patients have excellent prognosis and adjuvant RT therapy has no effect on prognosis. These patients have long survival time, adjuvant RT treatment should be considered in recurrence treatment.

Keywords: Endometrial stromal sarcoma, Surgery, Rare tumor

\section{GíRiș}

Endometrial stromal sarkom (ESS), uterin sarkomlar arasında en sık görülen 2. sarkom tipidir [1]. ESS, tüm uterin malignitelerin $\%$ 0.2-4'ü, tüm uterin sarkomların \%6-20'si kadardır [2-4]. ESS'ler genellikle leiomyom ön tanısıyla ameliyat edilir. Tanı histerektomi materyalinin histopatolojik incelenmesi ile konulur. ESS, genellikle uterin sarkomlu hastalara göre daha genç (45-57 yaş ortalamas1) yaşta ve premenopozal dönemde saptanır $[3,5,6]$.

ESS, ilk olarak 1966'da Norris ve Taylor tarafindan tanımland 1 ve siniflandirıldı [7]. Endometrial stromal tümörler, son olarak 2014 yılında dünya sağlık örgütü sınıflandırma sistemine göre: benign formu endometrial stromal nodül (ESN); malign formları düşük dereceli (low grade; LG-ESS), yüksek dereceli (high grade; HG-ESS) ve farklılaşmamış stromal sarkom (undifferentiated; U-ESS) olmak üzere alt gruplara ayrıldı [8]. Histopatolojik tanısı, parmak şeklinde myometrial invazyon alanları içeren, genellikle lenfovasküler alan invazyonuna sahip olan ve düşük mitotik aktiviteye ( $<5$ mitoz / 10 büyütme) sahip olması ile konur. Nükleer atipi ve nekroz yokluğunda, eğer mitoz sayısı 10 büyük büyütme alanında ondan fazlaysa yine ESS tanis1 konulur [9].

Patogenezi net değildir, ancak bazı vakalarda tamoxifen kullanımı ve karşılanmamış östrojen maruziyeti olduğu bildirilmiştir [10]. Primer tedavide östrojen maruziyetini azaltmak için bilateral salfingoooferektomi (BSO) yapılmalıdır [2,5]. ESS yüksek oranda östrojen ve progesteron reseptörü içerdiği için, hormonoterapiye iyi yanıt verir $[3,6]$. ESS'de prognostik faktörler; tümör boyutu, mitoz sayıs1, evre, histolojik grade, cerrahi marjin tutulumu, menopozal durum ve yaşdır [4,5]. Bu tümörler genellikle yavaş büyüme paternine sahiptir ve geç nüks ederler [6].

$\mathrm{Bu}$ çalışmanın amacı, çok merkezli olarak nadir görülen ve iyi prognoza sahip olan evre I LG-ESS hastalarının incelenmesi ve prognostik faktörlerin değerlendirilmesidir.

\section{YÖNTEMLER}

Tepecik eğitim ve araştırma hastanesi ve Zonguldak Bülent Ecevit üniversitesi tıp fakültesinde, evre I LG-ESS tanıs1 alan ve takiplere gelen 24 hasta incelendi. Çalışmaya 1998-2016 yılları arasında ESS tanısı alan, evre I olan ve ameliyatı ve takipleri bu iki merkezde olan hastalar dahil edildi. Çalışmaya dahil edilmeme kriterleri; tümörün endometrial stromal nodül veya farklılaşmamış stromal sarkom histolojik tiplerinde olması, evre II, III ve IV LG-ESS, eşlik eden başka malignitelerin olması ve hastaların takiplere gelmemesi olarak belirlendi.

Hastaların ameliyat öncesi yaş, tam kan sayımı ve ultrasound görüntüleri ve tümör boyutları incelendi. Hasta dosyalarından ameliyat tipleri, patoloji sonuçları, pelvik ve para-aortik lenf nodu sayıları, hastalıssı ve toplam sağkalım süreleri, adjuvan tedavi ve takiplerde nüks görülüp görülmediği analiz edildi. Taramalar retrospektif olarak yapıldı. Tüm ameliyatlar jinekolojik onkoloji uzmanları tarafindan yapıldı ve kendi merkezlerinde bulunan uzman jinekolojik patologlar tarafindan incelendi. 2014 yılından önce yapılan ameliyatlar 2014 dünya sağl1k örgütü sınıflandırma sistemine göre revize edildi [8]. 2009 FIGO (uluslararası jinekoloji ve obstetri federasyonu) evreleme sistemine göre evrelemeler tekrar gözden geçirildi [11]. $\mathrm{Bu}$ evrelendirme sisteminde bizim çalışmamızda yer alan evre I: sadece uterusa sinırlı tümörlerin (adneks tutulumu olmadan) olması olarak tanımlanmıştır. Evre IA $\leq 5 \mathrm{~cm}$, 
evre IB $>5 \mathrm{~cm}$ tümörün olması şeklinde alt gruplara ayrıldı. Hastalara ekstrafasiyal histerektomi ve bilateral salfingo-ooferektomi işlemi uygulandi. Pelvik lenfadenektomi eksternal, ana iliak damarlar ve obturator fossa üzerinde bulunan lenfatik dokuların alınma işlemi olarak tanımlandı. Para-aortik lenf nodu diseksiyonu inferior vena kava ve aort üzerinde bulunan sol renal damarlar ile bifurkasyon arasındaki lenf nodunun toplanmasıdır. Hastalar takiplerde ilk iki y1l 3 ayda bir, sonraki 2 y1l 6 ayda bir sonraki y1llarda ise y1lda bir kontrol edildi. Her kontrolde pelvik muayene, tüm batın ultrasonografi görüntülemesi ve tam kan sayımı yapıldı. Yılda bir batın ve toraks tomografisi çekilerek metastaz açısından tarama yapıldı.

\section{Istatistiksel analiz}

Sağkalım analizi Kaplan-Meier metodu ve logrank testi ile analiz edildi. Hastalıksız sağkalım (DFS) hastalığın tanı anından nüks anı veya son muayene anına kadar geçen süredir. Toplam sağkalım (OS) tanı ile ölüm veya son muayene tarihine kadar geçen süreyi ifade eder. Non-parametrik ve parametrik değerler karş1laştırılırken $\chi^{2}$ (Ki-kare) ve Student ttestleri kullanıldı. Prognostik faktörlerin nüks oluşumu üzerine etkileri lojistik regresyon analizi kullanılarak analiz edildi. Cox regresyon analizi sağkalım üzerine etki eden faktörleri saptamak için kullanıldı. Tüm istatistiksel analizler Windows için MedCalc sürüm 14.0 (MedCalc Software, Mariakerke, Belçika) kullanılarak yapıldı. $\mathrm{P}<0.05$ olan değerler istatistiksel olarak anlamlı kabul edildi.

\section{BULGULAR}

Evre I LG-ESS hastalarının klinik özellikleri tablo 1'de anlatıldı. Hastaların tamamında tümör sadece uterusa sinırlı (evre I) olarak saptand 1 ve hastalarda adneks tutulumu görülmedi. Hastaların $9(\% 37.5)$ tanesinde tümör boyutunun $5 \mathrm{~cm}$ ve daha küçük (evre IA) ve $15(\% 62.5)$ tanesinde tümör boyutunun $5 \mathrm{~cm}$ 'den daha büyük (evre IB) olduğu raporlandı. Hastaların \%66.6'sının premenopozal dönemde olduğu tespit edildi. Hastaların \%70.8'ine sadece cerrahi tedavi verilirken, \%29.2 hastaya cerrahinin yanında adjuvan radyoterapi verildi. Adjuvan tedavi olarak hiçbir hastaya internal radyoterapi verilmezken, 6 hastaya 4.5 Gy ve 1 hastaya 5.4 Gy eksternal radyoterapi verildi. Adjuvan kemoterapi verilmediği görüldü. Hormonoterapi olarak, $3(\% 12.5)$ hastaya megestrol asetat $(1 * 160 \mathrm{mg}) \quad$ verildi. Rekürrenslerin tedavisinde; inguinal lenf nodu metastazı olan hastaya sisplatin + farmarubisin (6kür), akciğer veya karaciğer metastazı olan hastalara doksorubisin + dakarbazin (6 kür) tedavisi verildi.

Yaş, adjuvan radyoterapi (RT), myometrial invazyon (MI), tümör boyutu ve mitoz sayısının lojistik regresyon analizine göre evre I LG-ESS hastalarında nüks oluşma riski üzerine etkileri tablo 2'de özetlendi. On büyük büyütme alanında $\geq 5$ mitoz olmasının, nüks riskini saptamada anlamlı ilişkili olduğu hesapland1 (tablo 2).

Prognostik faktörlerin DFS ve OS üzerine etkileri tablo 3'de anlatıld1. DFS ve OS üzerine istatistiksel olarak anlamlı etki eden prognostik faktör olmadığı saptandı (Tablo 3). Evre I, LG-ESS hastalarının, 5 yıllık OS \%100, 10 y1llık OS \%86.2 ve 5 y1llık DFS \%91.7 ve 10 yıllık DFS \%85.1 olarak hesapland.

\section{TARTIȘMA}

$\mathrm{Bu}$ retrospektif çok merkezli çalışmada, evre I LG-ESS tanılı 24 hasta araştırıldı ve prognostik faktörler ve sağkalım verileri incelendi. Erken evre LG-ESS hastalarının prognozunun mükemmel olduğu saptandı. Nüks riskini belirlemede incelenen faktörlerden, mitoz sayısının istatistiksel anlamlı olduğu bulundu. Literatürde LG-ESS hastalarına verilen adjuvan RT'nin nüks 
oluşumunu engellediği veya azalttığına dair tartışmalı sonuçlar mevcuttur ve bizim çalışmamızda ise adjuvan RT'nin nüks oluşumu ve sağkalım üzerine etkisi olmadığı görüldü.

Literatürde LG-ESS tanılı hastaların ortalama tanı yaşının 42.0-51.5 olduğu, \%60.085.7'ü premenopozal dönemde tan1 aldığ 1 raporlanmıştır [2-6]. Hastaların \%62.9-70.5'i evre I olarak saptanmıştır [2,4-6]. Hastaların \%17.5-57.1'ine BSO işlemi uygulanmamıştır $[3,4]$. Bizim çalışmamızda ortalama tanı yaşının $45.6 \pm 6.2$ olduğu ve hastaların \%70'inin premenopozal dönemde olduğu saptand 1 . Hastaların tamamında operasyona BSO işlemi eklendiği tespit edildi. Behtash ve ark. tarafından yapılan çalışmada evre I LGESS hastalarının ortalama OS süresi $73.5 \pm 35.09$ ay ve 5 y1llı OS oran $\% 95.0$ olarak belirtilmiştir [5]. Bizim çalışmamızda ortalama DFS süresi $99.3 \pm 11.2$ ay ve OS süresi $105.2 \pm 10.0$ ay olarak hesaplandı. Beş ve on y1llık DFS \%91.7-85.1 olarak ve beş ve on y1ll1k OS \%100.0-86.2 olarak saptand1.

$$
\text { Adjuvan radyoterapi ve }
$$

hormonoterapinin ESS hastalarında nüks oluşumunu azaltmadaki etkisi hakkında net konsensus yoktur ve yapılan çalışmalarda çelişkili sonuçlar mevcuttur. Adjuvan RT ve hormonoterapinin rekürrens gelişimini azaltmadığını belirten çalışmalar azınsanmayacak derecede çoktur [2,5,12]. Hatta pelvik nüksü kontrol altına almada dahi yetersiz olduğunu gösteren veriler mevcuttur [4]. Bilateral salfingo-ooferektomi yapılmayan hastalarda hormonoterapiye rağmen $\% 80$ hastada nüks, overlerde meydana gelmiştir [6]. Bizim çalışmamızda \%12.5 hastada metastaz meydana geldi ve adjuvan tedavi alan \%29.2 hasta mevcuttu. Lojistik regresyon analizine göre, adjuvan tedavi alan hastaların nüks oluşma riskini azaltmada istatistiksel olarak anlamsız olduğu saptandı. Nüksler 8-15 ve 93 . aylarda meydana geldi. $\mathrm{Bu}$ verilere bağl1 olarak, adjuvan tedavinin ESS hastalarında nüks riskini azaltmadığı sonucuna varıldı.
Özellikle hormonoterapinin artan popülaritesine aldanarak bilateral salpingoooferektomiden kaçınılması eksik tedavi sonucu; nüks ve hastalıkla ilişkili ölüm oranlarında artışa neden olabilir.

Endometrial stromal sarkomlu hastaların sağkalımları genellikle çok iyidir. Bizim çalışma grubumuzda yer alan evre I hastalar gibi erken evreler için özellikle mükemmel prognoza sahiptirler. Literatürde yer alan çalışmalarda sağkalım süresi ve nüks oluşumu üzerine etki eden faktörler incelenmiştir. Derin myometrial invazyon varlığı, ooferektomi yapılmaması ve pelvik lenfadenektomi işleminin cerrahi prosedüre eklenmemesinin sağkalımı negatif etkilediği gösterilmiştir [4,5]. Nüks gelişimini öngörmede anlamlı bulunan prognostik faktörlerin; tümör boyutu ve artmış mitotik aktivite varlığı olduğu önceki çalışmalarda bulunmuştur [2,9]. Bizim çalışmamızda, 10 büyük büyütme alanında $\geq 5$ mitoz olmas1, nüks gelişme riskini istatistiksel olarak anlamlı derecede arttırdığ 1 saptandı. Ancak cox regresyon analizine göre, prognostik faktörlerin DFS ve OS süreleri üzerine anlamlı etkilerinin olmadığı bulundu.

$\mathrm{Bu}$ çalışmada bazı eksik yönler ve kısıtlamalar bulunmaktadır. En önemlilerinden bir tanesi, retrospektif çalışma tasarımının doğal sınırlamalarına sahiptir. Çalışmanın retrospektif doğası gereği, dosyalarda eksik olan veya bilgisayar kayıtlarından ulaşılamayan verilerin olması çalışmayı negatif yönde etkilemektedir. Ek olarak, 18 y1l boyunca az sayıda hasta, farklı cerrahlar tarafından ameliyat edilemeleri ve farklı tedavi rejimleri kullanılması, karşılaştırmaları potansiyel olarak olumsuz yönde etkileyebilecek diğer sinılayıcı faktörlerdendir. $\mathrm{Bu}$ kısıtlamalara rağmen, bizim çalışmamız, spesifik endometrial stromal sarkom grubu nedeniyle önemli bulgulara sahiptir. Bu çalışmanın güçlü yönleri, çok merkezli ve güvenilir veriler içermesidir. Diğer güçlü yönü ise tüm cerrahi örneklerin uzman 
jinekolojik patologlar tarafindan değerlendirilmesidir.

\section{SONUÇ}

Sonuç olarak, ESS hastaları mükemmel prognoza sahiptir ve adjuvan RT tedavisi prognoz üzerine etki etmemektedir. Sağkalım süreleri uzun olan bu hastalarda adjuvan RT işlemi nüks tedavisine saklanmalıdır. Ancak hormonoterapinin prognoz üzerine etkileri yeterli sayıda hasta grupları ile prospektif çalışmalarla incelenmelidir.

Finansal destek veya çıkar çatışması: Yoktur

Tablo 1. Çalışma grubunun klinik özellikleri

\begin{tabular}{|lc}
\hline Yaş (Ort \pm std); yıl & $45.6 \pm 6.2$ \\
\hline Tümör boyutu (Ort \pm std); cm & $5.6 \pm 2.7$ \\
\hline Cerrahi; sayı (\%) & $17(\% 70.8)$ \\
Cerrahi + Radyoterapi; sayı (\%) & $7(\% 29.2)$ \\
\hline Histerektomi + BSO; sayı (\%) & $16(\% 66.7)$ \\
\hline Histerektomi + BSO + PPLND; sayı (\%) & $8(\% 33.3)$
\end{tabular}

$10 \mathrm{Hfr}<5$ mitoz; sayı (\%)

\begin{abstract}
Nüks; sayı (\%)
Akciğer

$1(\% 4.2)$

Karaciğer

İnguinal lenf nodu

Hastalıksız sağkalım (Ort \pm std); ay

$($ Ort \pm std. $=$ Ortalama \pm standard sapma, $\mathrm{BSO}=$ Bilateral salfingo-ooferektomi, PPLNÖ=Pelvik paraaortik lenf nodu örneklemesi, $10 \mathrm{Hfr}=10$ büyük büyütme alanı, PLN=Pelvik lenf nodu, PaLN=Paraaortik lenf nodu)
\end{abstract}


Tablo 2. LG-ESS' de lojistik regresyon analizi ile nüks üzerine prognostik faktörlerin etkisi.

\begin{tabular}{|c|c|c|c|c|c|c|}
\hline & \multicolumn{3}{|c|}{ Univaryant Analiz } & \multicolumn{3}{|c|}{ Multivaryant Analiz } \\
\hline & OR & $95.0 \% \mathrm{CI}$ & $\mathbf{P}$ & OR & $95.0 \% \mathrm{CI}$ & $\mathbf{P}$ \\
\hline Yaş $(\geq 48)$ & 0.7 & $0.1-8.5$ & 0.755 & -2.5 & $-0.4-0.0$ & 0.189 \\
\hline Adjuvan radyoterapi & 0.2 & $0.1-2.1$ & 0.162 & -1.6 & $-0.4-0.0$ & 0.998 \\
\hline Myometriyal invazyon (>1/2) & 1.2 & $0.1-15.8$ & 0.873 & -0.4 & $-0.3-0.2$ & 0.096 \\
\hline Tümör boyutu ( $\geq 5 \mathrm{~cm}$ ) & 4.0 & $0.1-39$ & 0.993 & 0.6 & $-0.1-0.3$ & 0.998 \\
\hline Mitoz ( $\geq 5$ mitoz) & 6.4 & $6.0-7.4$ & 0.001 & 6.2 & $4.0-6.7$ & 0.010 \\
\hline
\end{tabular}

Tablo 3. Cox regresyon analizi ile prognostik faktörleri DFS ve OS üzerine etkileri.

\begin{tabular}{|c|c|c|c|c|c|c|}
\hline & \multicolumn{3}{|c|}{ Hastalıksız Sağkalım } & \multicolumn{3}{|c|}{ Toplam Sağkalım } \\
\hline & HR & $95,0 \%$ CI & $\mathbf{P}$ & HR & $95,0 \%$ CI & $\mathbf{P}$ \\
\hline Yaş $(\geq 48)$ & 18.5 & $0.0-5.2$ & 0.838 & 5.9 & $0.0-2.6$ & 0.340 \\
\hline Adjuvan radyoterapi & 8.9 & $0.0-4.0$ & 0.978 & 145.7 & $0.0-1.2$ & 0.954 \\
\hline Myometriyal invazyon (>1/2) & 2.2 & $0.0-8.6$ & 0.922 & 0.8 & $0.0-15.3$ & 0.851 \\
\hline Tümör boyutu ( $\geq 5$ cm) & 0.4 & $0.0-8.4$ & 0.883 & 189.4 & $0.0-2.7$ & 0.957 \\
\hline $\operatorname{Mitoz}(\geq 5$ mitoz) & 0.1 & $0.0-1,8$ & 0.936 & 0.1 & $0.0-1.7$ & 0.398 \\
\hline
\end{tabular}

\section{REFERANSLAR}

1. Garg G, Shah JP, Toy EP, Bryant CS, Kumar S and Morris RT. Stage IA vs. IB endometrial stromal sarcoma: does the new staging system predict survival? Gynecol Oncol 2010;118(1):8-13.

2. Kim DY, Lim KT and Kwon YS. Endometrial Stromal Sarcomas: A clinico-pathological analysis of 27 patients. Pak J Med Sci. 2013;29(1):72-76.

3. Ashraf-Ganjoei $\mathrm{T}$, Behtash $\mathrm{N}$, Shariat $\mathrm{M}$ and Mosavi A. Low grade Endometrial Stromal Sarcoma of uterine corpus, a clinicopathological and survey study in 14 cases.
World Journal of Surgical Oncology 2006, 4:50.

4. He L, Li JD, Xiong Y, Huang X, Huang L, Lin J, Zhou Y and Zheng M. Clinicopathological and molecular markers associatedwith prognosis and treatment effectiveness of endometrialstromal sarcoma: a retrospective study in China. Arch Gynecol Obstet (2014) 289:383-391.

5. Behtash N, Akhavan S, Gilani MM, Mousavi AA, Ghaemmaghami F, and Mazhari MM. Low Grade Endometrial Stromal Sarcoma of Uterine: Review of 17 Cases. Acta Medica Iranica, 2011; 49(9): 619-624.

6. Yamazaki H, Todo Y, Mitsube K, Hareyama H, Shimada C, Kato H and Yamashiro K. Long- 
term survival of patients with recurrent endometrialstromal sarcoma: a multicenter, observational study. J Gynecol Oncol, 2015, Vol. 26, No. 3:214-221.

7. Norris HJ and Taylor HB. Mesenchymal tumors of the uterus. I. A clinical and pathological study of 53 endometrial stromal tumors. Cancer. 1966;19:755-766.

8. Ali RH and Rouzbahman M. Endometrial stromal tumours revisited: an update based on the 2014 WHO classification. J Clin Pathol 2015;68:325-332.

9. Feng W, Malpica A, Skaland I, Gudlaugsson E, Robboy SJ, Dalen I, Hua K, Zhou X and Baak J. Can Proliferation Biomarkers Reliably Predict Recurrencein World Health Organization $2003 \quad$ Defined EndometrialStromal Sarcoma, Low Grade? Plosone 2013 vol 8
10. Feeley KM, Burton JL, Wells M. A diagnosticapproach to endometrial biopsies: selected topics. Curr Diagn Pathol 2000;6(1):13-20.

11. Amant $F$, Floquet $A$, Friedlander $M$, Kristensen G, Mahner S, Nam E, Powell M, Ray I, Siddiqui N, Sykes P, Westermenn A and Seddon B. Gynecologic Cancer InterGroup (GCIG) Consensus Review for Endometrial Stromal Sarcoma. Int $\mathrm{J}$ Gynecol Cancer 2014;24: S67-72.

12. Landreat V, Paillocher N, Catala L, Foucher F, Descamps $\mathrm{P}$ and Leveque J. Low-grade Endometrial Stromal Sarcoma of the Uterus: Review of 10 Cases. AnticancerResearch, 2008, 28: 2869-2874. 